\title{
Life-history traits correlate with temporal trends in freshwater fish populations for common European species
}

\author{
Raphaël Santos $^{1,2}$ (D) | Nicolas Poulet ${ }^{3}$ | Aurélien Besnard ${ }^{1}$ (D)
}

${ }^{1}$ EPHE, PSL Research University, CNRS, INRA, UMR 5175 CEFE, Montpellier, France ${ }^{2}$ HES-SO / HEPIA, University of Applied Sciences and Arts of Western Switzerland, Ecology and Engineering of Aquatic Systems Research Group, Jussy, Switzerland

${ }^{3}$ Pôle Ecohydraulique, Agence Française pour la Biodiversité, Institut des Mécaniques des Fluides, Toulouse, France

\section{Correspondence}

Raphaël Santos, EPHE, PSL Research University, CNRS, UM, SupAgro, IRD, INRA, UMR 5175 CEFE, F-34293 Montpellier, France.

Email: contact@raphael-santos-aquaticbiologist.com

Funding information

French Agency for Biodiversity

\begin{abstract}
1. Understanding the population dynamics of aquatic species and how inter-specific variation in demographic and life history traits influence population dynamics is crucial to define their conservation status and design appropriate protection measures.

2. The abundance and biomass growth rates for 18 common European freshwater fish species were estimated using data spanning 1990-2011 for 546 sites across France. Fish-length trends were assessed using quantile regressions and correlations with life history traits were investigated.

3. Amongst the 18 species, eleven of them have exhibited a significant decline in abundance and 14 species declined in biomass, seven remained stable or exhibited positive abundance growth rates; for four species, biomass was stable or increased. Of the demographic and ecological traits investigated, life-history strategy and maximum length were significantly correlated with species' population growth rates, revealing that the decline mainly concerned large-bodied species with slow life-histories.

4. These results focus on 18 common European species representing $94 \%$ of fish captured during the study period within the French national monitoring programme and underline that more attention should be paid to the decline in common species. Population dynamics of widely distributed common species are key drivers of communities and of importance to ecosystem function.

5. This study provides evidence of declines in common European freshwater fish species at a national scale and recommends conservation measures to favour recovery of most declining species. We highlight the crucial value of electrofishing monitoring programmes to assess freshwater fish species population trajectories and to support environmental management and conservation policy based on scientific evidences.
\end{abstract}

\section{KEYWORDS}

abundance, biomass, demographic strategy, fish length trends, fish population dynamics, population decline

\section{1 | INTRODUCTION}

Water resource management is a major global issue for economic and developmental reasons, but it also represents a significant biodiversity conservation concern (Millennium Ecosystem assessment, 2005; Balian et al., 2008). Freshwater ecosystems host at least $9.5 \%$ of described animal species, many of which are threatened by global or local pressures from anthropogenic activities 
(Décamps, 2011; Helfman, 2007). In Europe, human activities have degraded the morphology, hydrology, continuity, water quality, and water quantity of more than $70 \%$ of waterbodies, which in turn impacts biodiversity (European Environment Agency, 2012, 2018). As a result, fish are the second most-threatened taxa in Europe, with $37 \%$ of species considered as threatened by extinction and $2.5 \%$ as extinct, mostly salmonid species (Freyhof \& Brooks, 2011). The situation is similar in North America, where between 21 and 39\% of described freshwater fish species are imperilled or threatened with extinction, and $3 \%$ are already extinct (Jelks et al., 2008; IUCN Red List, 2018). Worldwide, according to the International Union for Conservation of Nature (IUCN) Red List, 23\% of currently listed ichthyofauna are considered as vulnerable, endangered, or already extinct (IUCN Red List, 2018).

To monitor fish populations, field sampling protocols have been deployed, such as monitoring programmes implemented within the European Water Framework Directive (EU-WFD; 2000/60/EC) or the United States Clean Water Act (Public Law 92-500, 1972). The data from these surveys have been mainly used to assess disturbances to freshwater fish communities through ecological indices (Karr, 1981; Logez, Bady, Melcher, \& Pont, 2013; Schmutz et al., 2007). While fish indices provide relevant information at the scale of a community reflecting the level of degradation of fish assemblages (Marzin et al., 2012; Santos et al., 2017), they should be supplemented by population dynamic analyses to assess species population trends. Understanding the population dynamics and, ultimately, the population growth rate $(\lambda)$ of aquatic species is crucial to define species conservation status, and in turn to implement relevant conservation strategies for restoring river biodiversity, notably by focusing on the most-threatened species in decline.

Apart from determining population growth rate, understanding how inter-specific variation in demographic and life history traits influences population dynamics is crucial information for environmental managers. It is essential to identify which intrinsic ecological traits may render some species more vulnerable and contribute to risk factors in population decline. This information also allows the main drivers of population dynamics to be identified, so that relevant management actions can be proposed (Velez-Espino et al., 2006; Winemiller, 2005). For instance, species' trophic position, generation time (life history traits) and life traits related to species' sensitivity to climate change are of overriding importance in predicting extinction risks both in aquatic and terrestrial taxa (Cardillo et al., 2008; Julliard et al., 2003; Lebreton, 2011; Møller et al., 2008; Reynolds et al., 2005; Reynolds Webb et al., 2005; Kopf et al., 2017). Correlations between a species' generation time, size, population decline, and subsequent conservation status have been highlighted in many taxa, such as mammals, birds, reptiles, and marine fish (Winemiller, 2005; Saether \& Engen, 2002; Gaillard et al., 2005; Reynolds, et al., 2005; Böhm et al., 2013). Large-sized long-lived species have been found to suffer most from anthropogenic pressures as their low population density and low intrinsic maximum population growth rate limit their ability to recover after perturbations (Stearns, 1992; Saether \& Engen, 2002; Lebreton, 2011). In contrast, small-sized short-lived species can rapidly recover after disturbance due to high intrinsic maximum population growth rate (Gaston \& Blackburn, 1995; Lebreton, 2011; Schipper et al., 2008).

In fish, three main life history strategies are recognised: (1) largesized long-lived species maturing late and having high fecundity are considered periodic species with slow life histories; (2) smallsized short-lived species maturing early are considered opportunist strategists with fast life histories; and (3) species that maximise juvenile survival through parental care are considered equilibrium species (Winemiller \& Rose, 1992). Olden et al. (2007) underline that body-size distributions of at-risk freshwater fishes are bimodal. Both small- and large-bodied freshwater species are threatened by global extinction, especially large-bodied anadromous species (Reynolds, et al., 2005; Olden et al., 2007). Reynolds, et al. (2005), Winemiller (2005), and Kopf et al. (2017) have shown that in Europe and North America, small-bodied freshwater fish species are more threatened with extinction than larger fish. However, among small-bodied species, some of them listed in the IUCN Red List of Extinction Risks and the U.S. Fish and Wildlife Service list of threatened and endangered species are listed solely because of their small range size and their restriction to one catchment (Freyhof \& Brooks, 2011; Reynolds, et al., 2005; Winemiller, 2005; Kopf et al., 2017). While a small range increases extinction risk, it does not necessarily translate into population decline. Therefore, fish species at risk of extinction according to the IUCN criteria are not necessarily declining whereas widely distributed, common species could be far from extinction but declining nonetheless (Gaston \& Fuller, 2008; Inger et al., 2015). Therefore, freshwater fish population dynamics should be further investigated to supplement IUCN Red List of extinction risk status. Correlations between freshwater fish life history traits (especially demographic traits) and population dynamics should also be assessed to identify most vulnerable species; especially in widely distributed species not listed at risk of extinction for which even small variations in the abundance and biomass might result in substantial modifications of structure, function, and dynamics of communities at a large geographic scale (Gaston, 2010; Gaston \& Fuller, 2008).

In this study, we investigated firstly fish trends in abundance, biomass, and fish body length in France for the period 1990-2011. These three biological metrics provide complementary information on the structure of fish populations. Secondly, we assessed whether species' demographic and biological traits (life history strategies, trophic position, habitat preferences, and thermal tolerance) were correlated with population dynamics. We focused on 18 common European species that together composed the majority of individuals and biomass (94.1\% of fish abundance and $88.4 \%$ of fish biomass) captured in annual monitoring surveys during the study period.

\section{2 | MATERIALS AND METHODS}

\section{1 | Study area and fish sampling method}

The monitoring programme started in 1990 and is ongoing, investigating freshwater fisheries of selected rivers across France (Figure 1). 
Sampling was carried out by the French Office for Biodiversity (formerly the French National Agency for Water and Aquatic Environments), which sampled the freshwater fish communities using standardised electrofishing protocols. The sampling protocol depended on river width and depth during low-flow seasons and was conducted either in spring or autumn (see Poulet et al., 2011 for more details). Captured fish were identified, counted, measured, and weighed before being released back into the river. When juveniles were sampled, to avoid mortality of this sensitive stage during handling, fish were pooled together according to their size. They were counted, and then the body lengths of at least 30 individuals from the same pool were measured, and finally the fish in the pool were weighed together.

\section{2 | Fish monitoring data}

\subsection{1 | Abundance and biomass}

From the survey sampling data for hundreds of monitored sites, we selected a total of 546 sites homogeneously distributed in France (excluding sites in Corsica and overseas France) sampled between 1990 and 2011 in order to analyse only the longest available time series (ranging from 7 to 22 years with an average of 12 sampled years per site; Figure 1). To compare interannual abundance (as the number of fish captured) and biomass (as the total weight of fish captured), we selected a final dataset including 6,483 sampling events within these 546 sites, which were surveyed with the same protocol and in the same season (either spring or autumn). Abundance and biomass growth rates were assessed for 18 fish species in France representing $94.1 \%$ of the captured fish abundance and $88.4 \%$ of fish biomass of the $3,300,609$ fish sampled (Table 1). At the time of the monitoring programme, some of the 18 investigated species were considered as distinct species, but recent taxonomic analyses consider that some of them include several newly identified species (Kottelat \& Freyhof, 2007). For instance, one species identified since 1990 in the monitoring programme as Leuciscus leuciscus has more recently been defined by genetic and morphological analyses as five distinct species distributed in France (Costédoat et al., 2006; Kottelat \& Freyhof, 2007). In such cases, we considered Leuciscus spp. as a taxonomic unit pooling together the five distinct species. In the same way, Gobio spp. refers to three species previously considered as Gobio gobio; Cottus spp. refers to eight species previously considered as Cottus gobio; and Phoxinus spp. refers to three species previously considered as Phoxinus phoxinus.

\subsection{2 | Fish length}

We analysed fish length data for the 18-investigated taxa at the 546 sites for the period between 1995 and 2006. We restricted our analysis to these 12 years during which more than 320 sites were sampled each year to maximise the total number of fish-length
FIGURE 1 Spatial distribution of the 546 sampling sites (black dots) and main rivers (grey lines) in metropolitan France. Corsica was excluded due to the low number of data available

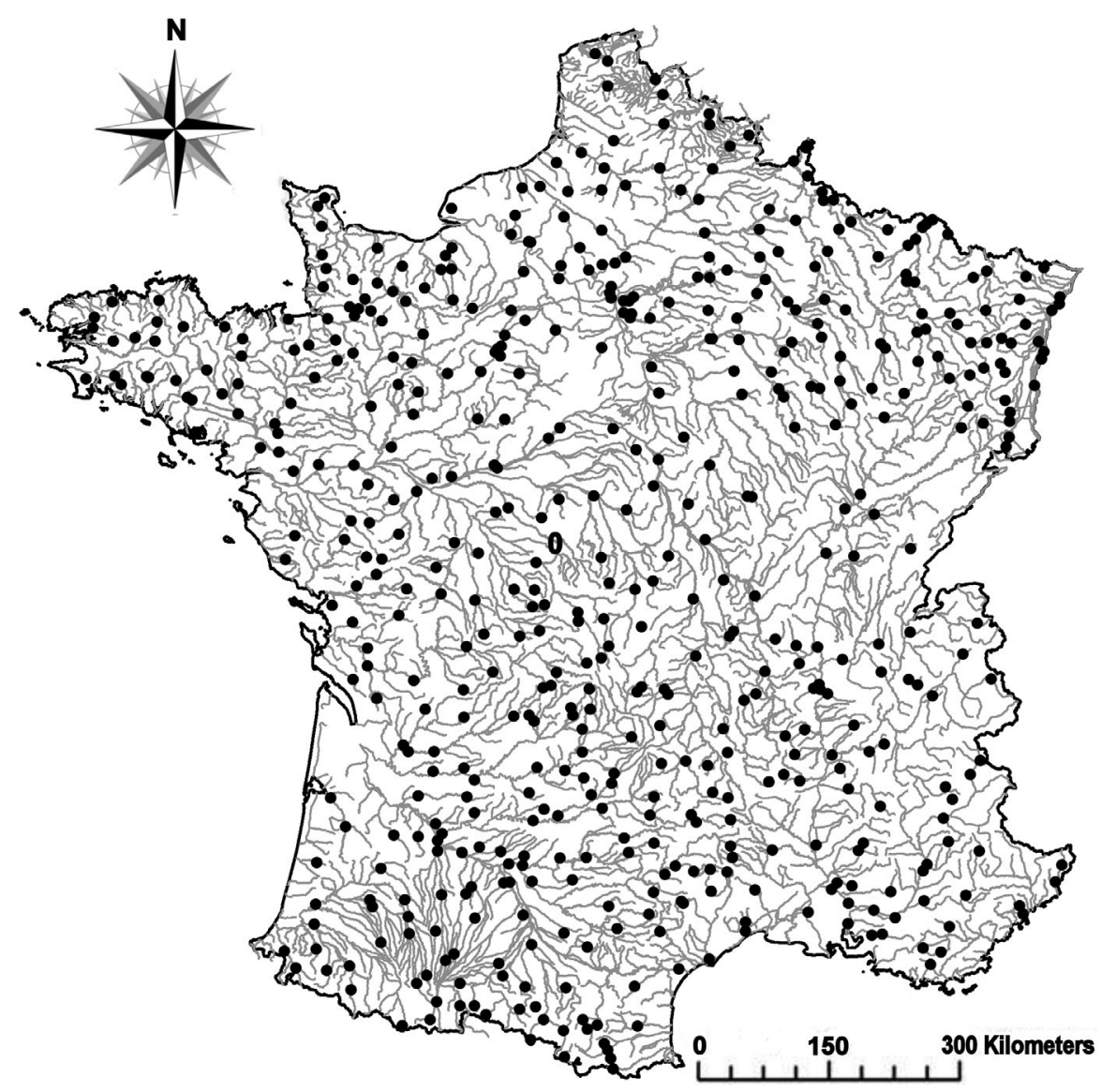




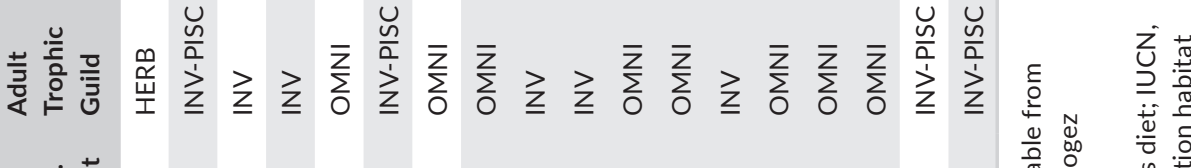

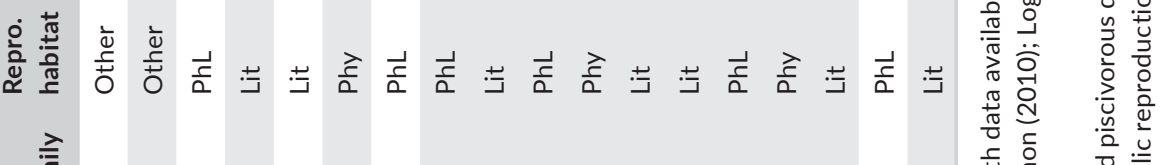

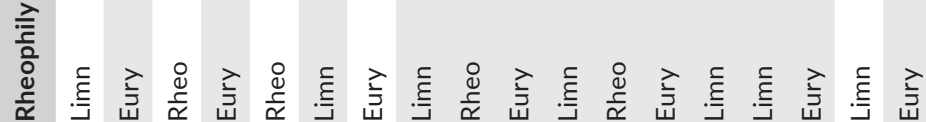

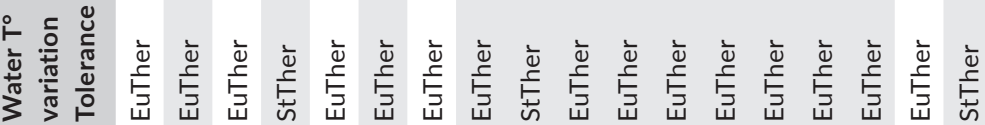

离占范

$\stackrel{\infty}{\stackrel{\infty}{1}}$

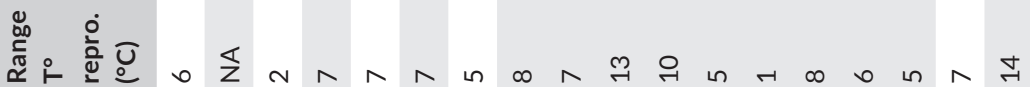

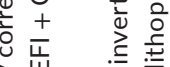

$\stackrel{0}{0}$

党

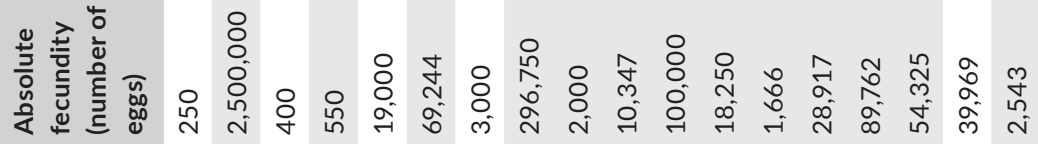

8

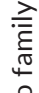

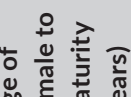

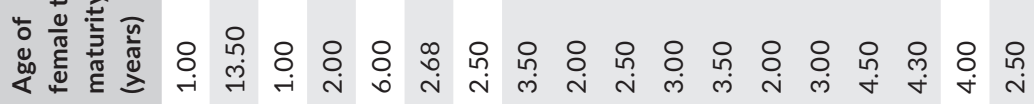

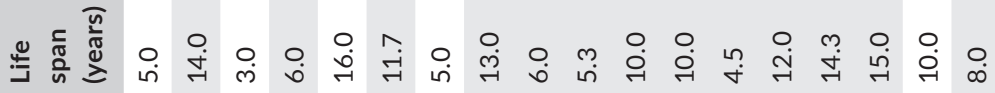

है

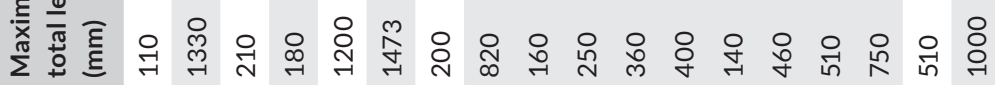

己纪焉离

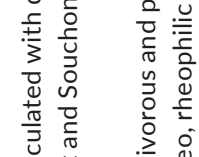

嵌

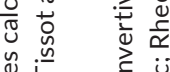

出

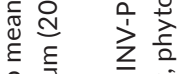

$\frac{0}{\tilde{v}}$

$\frac{n}{4}$

离

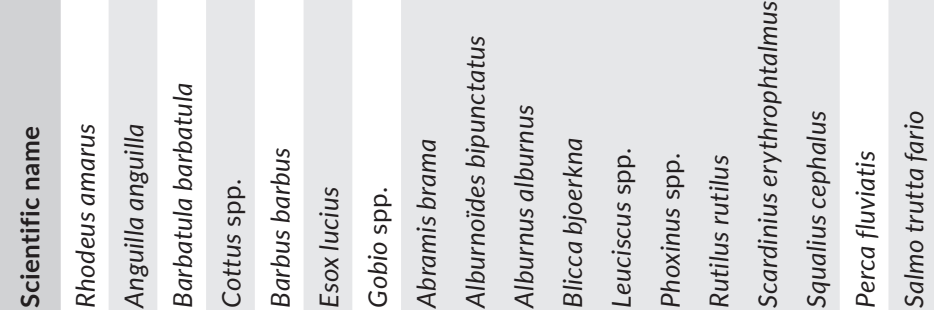

일

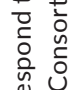

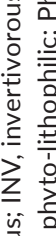

离

일

完

岂岌

嵌

हो $\bar{z} \frac{\overline{0}}{0}$

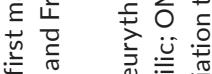

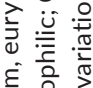

产焉

吾苛

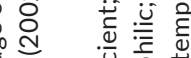

离

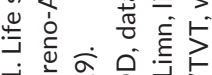

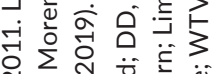
N)

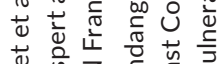

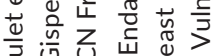

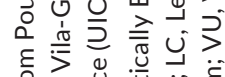

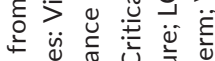

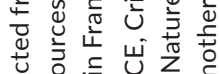

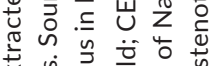

离

$\stackrel{\infty}{\stackrel{\infty}{\Perp}}$

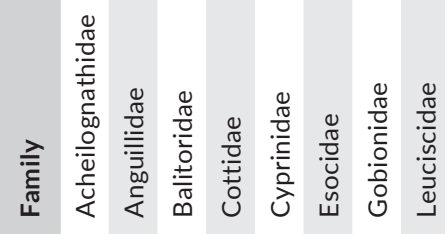


measurements available per year. Only fish sampled in autumn were analysed to avoid body length variation due to the sampling season. Depending on species abundance, fish-length trends were investigated using sample sizes ranging from 4,437 (Esox lucius) to 533,992 (Phoxinus spp.) individuals with a mean of 110,111 fish per species.

\subsection{3 | Ecological and biological traits}

To describe species' life history strategies, we considered the lifespan, age at maturity of females and mean absolute fecundity. Values for these parameters were extracted from Vila-Gispert and Moreno-Amich (2002), Kottelat and Freyhof (2007), and FishBase (Table 1). Mean values were calculated with data available from western and central Europe countries. The other investigated ecological traits were extracted from the classification completed during the EFI + project (Holzer, 2008; EFI + Consortium, 2009; Logez et al., 2013) and from Tissot and Souchon (2010). Ecological traits we examined included species' adult trophic guild, maximum reproduction temperature, range of reproduction temperature, and habitat (affinity to flow velocity and reproduction habitat; Table 1).

\section{3 | Statistical analysis}

\subsection{1 | Abundance and biomass growth rate modelling}

Field-based estimates of abundance and biomass entail uncertainty because of stochasticity and observation errors (De Valpine \& Hastings, 2002; Kéry \& Schaub, 2012; Newman et al., 2014). To tackle these limitations, we used Bayesian state-space models, modelling an observation process and a state process to assess abundance and biomass trends separately for each species (Figure 2). State-space models are time series models in which the true state of the population size observed each year is modelled considering the observed data and accounting for observation errors. In the present work, observed values $C_{[i, t]}$ correspond to count or biomass data at site [i] and time [t] for a particular species as recorded in the field. They are modelled in the observation equation using a log-normal distribution to model the observation process given by:

$$
\log \left(C_{[i, t]}\right) \sim N\left(\log \left(N_{[i, t]}\right), \sigma_{\text {obs }[i]}^{2}\right) .
$$

with $N_{[i, t]}$ the true abundance or biomass at the considered sampling event and sigma the site-specific variance $\left(\sigma_{\text {obs }[i]}^{2}\right)$. As previously stipulated by Furrer et al. (2016), this observation model assumes that log-transformed abundance or biomass values are correct on average and adjusted for site-specific residual variance to consider both site-specific observation errors and species-specific detection errors (source code of the model see Appendix S1). The true population size and biomass values $\left(N_{[i, t]}\right)$ are linked through a dynamic state process by the state equation assuming an exponential intrinsic growth $r_{[i, t]}$, of the population on site [i] from year [t] to $[t+1]$ given by:

$$
\log \left(N_{[i, t+1]}\right)=\log \left(N_{[i, t]}\right)+r_{[i, t]}-\log \left(S_{[i, t]}\right)+\log \left(S_{[i, t+1]}\right) \text {. }
$$

where $\left(S_{[i, t]}\right)$ is the value of the surface area sampled (in $\mathrm{m}^{2}$ ) to consider interannual sampling effort variability (i.e. an offset) and $\left(r_{[i, t]}\right)$ is the site-specific interannual population growth rate of mean $-r_{[i]}$ and variance $\sigma r_{[i]}^{2}\left(r_{[i, t]} \sim N\left(-r_{[i]}, \sigma r_{[i]}^{2}\right)\right)$. Site-specific growth rates for each species were modelled as normally distributed around a nation-wide mean growth rate $r_{\text {nat }}$ with a site random effect; $-r_{[i]} \sim N\left(r_{\text {nat }}, \sigma r_{\text {nat }}{ }^{2}\right)$ where $\sigma r_{\text {nat }}{ }^{2}$ is the variability of the mean growth rate among sites. It is possible to assess density dependence using state-space models applied to long time-series (Knape \& De Valpine, 2012). However, intrinsic processes leading to density dependence are complex to estimate on relatively short times series (12 years on average in this study) with no intra-annual replication and possible delayed effects (Fromentin et al., 2001). Therefore, in this study we did not include density-dependence estimates in our models considering the limitations of data available, that most of the species were declining or stable and that our main objective was to estimate fish population trends in abundance and biomass; trends which intrinsically include site-specific density dependence processes.

Vague priors were specified for all the parameters. We computed three MCMC-chains of 1,500,000 iterations to fit the data and discarded the first 500,000 iterations to remove the initial conditions. The remaining iterations, thinned by 50 , were used for inference. MCMC-chains were performed using JAGS (Plummer, 2003) launched through the R package runjags (Denwood, 2016). Growth rates were considered as significant if posterior distribution ( $95 \%$ credible interval) excluded zero. Chain convergence was assessed visually and using the BrooksGelman-Rubin criterion (Rhat). We achieved convergence with all Rhat $<1.01$ (Brooks \& Gelman, 1998). Posterior predictive checks of the 36 models were done graphically comparing observed counts to their predicted median values from the posterior distribution (Appendix S2).

\subsection{2 | Trends in fish length over time}

Rather than modelling the conditional mean of a response variable commonly performed by standard least-squares regressions, quantile regressions can be used in a linear model to model parts of the distribution corresponding to various quantiles' $\tau$ values (Koenker, 2005). This regression method is distribution-free and provides a more complete picture of the relationships between variables than other regression analyses (Cade \& Noon, 2003; ChamailléJammes \& Blumstein, 2012). In our study, fish lengths (y) of each of the 18 species were modelled over time (between 1995 and 2006) for five quantile intervals: $\tau=0.1,0.25,0.5$ (median value), 0.75 , and 0.90 to provide complementary information to the trend in median fish length (Figure 2). We performed quantile regressions with 


\section{Data}

Analyses and outputs

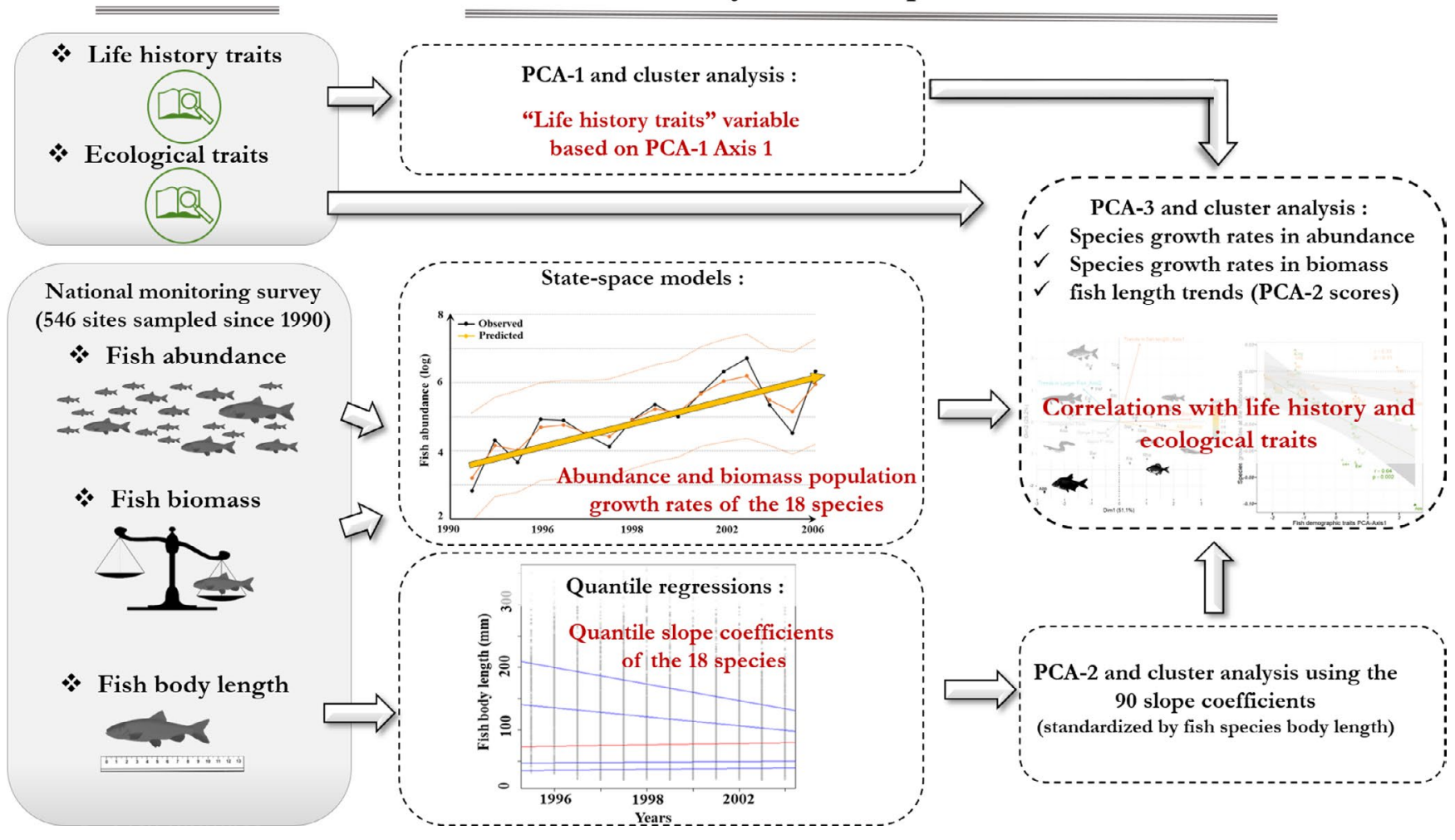

FIGURE 2 Illustration of the workflow implemented in this research work. The data from the literature or the French national monitoring survey were analysed through a combination of statistical analyses including state-space models, quantile regressions, and multivariate and cluster analyses. PCA, principal component analysis [Colour figure can be viewed at wileyonlinelibrary.com]

R 3.2 (R Development Core Team, 2015) in the package quantreg (Koenker, 2015).

\subsection{3 | Correlation between ecological traits, fish length, and demographic trends}

To describe life history strategies, we performed a standardised principal component analysis (PCA) combining three demographic traits: absolute fecundity, lifespan, and age to female maturity (PCA1). The mean absolute fecundity was log-transformed prior to analysis. Anguilla anguilla was excluded from the analysis because in a preliminary PCA this species explained $70 \%$ of inertia in the first axis due to its extreme age at maturity and fecundity values (Table 1). Maximum body length was added to PCA-1 as a supplementary variable. Supplementary variables have no influence on the principal component as they are projected a posteriori but add supplementary information that can guide the interpretation of the PCA results (Husson et al., 2015). Species' scores on the PCA-1 first axis were then used as a new synthetic life history trait variable (Figure 2).

To summarise the quantile regression analysis and to have an overview of the results, we implemented a second standardised PCA with the five-quantile regression coefficients estimated for each of the 18 species (PCA-2). The quantile regression coefficients were first divided by median fish length to compare trends between species independent of their body size. Species scores on the first two axes were then used as new synthetic variables summarising body length trends (see Figure 2; Results 3.3). The PCA-1 life history trait variable and maximum body length (log-transformed) available from Poulet et al. (2011) were added to PCA-2 as supplementary variables.

Finally, we conducted a third PCA to analyse correlations among trends in abundance, biomass, and fish length (PCA-3). For each of the 18 species, we included the abundance and biomass growth rates as well as species scores from the first and second axes of the fish-length trends from PCA-2 (Figure 2). The quantitative PCA-1 life history trait variable, maximum body length (log-transformed), thermal tolerance parameters and other qualitative ecological traits (adult trophic guild, affinity to flow velocity and reproduction habitat) were added as supplementary variables to investigate their correlations. Statistical significance of between-group differences for qualitative variables was assessed using between-class analyses and permutation tests (Dray et al., 2007). Further linear regressions were computed to assess the relationships between species trends in abundance/biomass and most correlated quantitative biological traits. Multivariate analyses were performed with the R packages FactoMineR and ade4 (Dray et al., 2007; Husson et al., 2015). Hierarchical clustering analyses were performed using Ward's criterion to group species according to their similarities. Multiscale bootstrap resampling ( $n=10,000$ ) was performed to assess uncertainty of the hierarchical cluster analyses (Suzuki \& Shimodaira, 2006). The optimal number of clusters was defined by 
gap statistics. Bootstrap probability*100 values corresponding to the frequency that a cluster appears in the bootstrap replicates and approximately unbiased probability values *100 (AU; $p$-values) were computed. Statistical significance was defined at $p \leq 0.05$ and $A U \geq 95$.

\section{3 | RESULTS}

\subsection{Demographic traits of common fish species}

The first factorial plane of PCA-1 performed with three demographic traits explained $97 \%$ of the total variance (Figure 3a). Principal component analysis- 1 axis- 1 , which explained $87.2 \%$ of the total variance was correlated with the species' lifespan (0.93) and age at maturity (0.86), and to a lesser extent the species' absolute fecundity (0.81) and maximum body length (0.65), analysed as a supplementary variable. Hierarchical clustering grouped species with lower life span, lower age of female at first maturity and lower fecundity including Rhodeus amarus, Barbatula barbatula, Cotus spp., Gobio spp., Alburnoides bipunctatus, Phoxinus spp., Alburnus alburnus, and Salmo trutta in a first cluster significantly different from the others ( $p<0.05$; $A U=97$; Figure $3 b$ ). Species Perca fluviatilis, Leuciscus spp., Abramis brama, Blicca bjoerkna, Esox lucius, Rutilus rutilus, and Barbus barbus, Squalius cephalus, and Scardinius erythrophtalmus were gathered in second and third clusters characterised by higher life span, higher age of female at first maturity, and higher fecundity grouping larger bodied species with slow life-history traits. Species from the third cluster were significantly discriminated ( $p<0.05 ; \mathrm{AU}=97$ ) from species from the second cluster due to the higher age of female at maturity and lower fecundity. Species-specific scores on the first axis were used to create a new synthetic demographic trait variable discriminating fish species according to their life histories on a slow-fast life history strategy continuum.

\section{2 | Fish abundance and biomass growth rates}

A high correlation between abundance and biomass growth rates at the national scale $\left(r_{\text {nat }}\right)$ was observed $(r=0.84)$. Of the 18-species investigated, population growth rates in abundance were negative for 11 species (A. alburnus, A. anguilla, B. bjoerkna, A. brama, E. lucius, R. rutilus, Gobio spp., P. fluviatilis, S. erythrophtalmus, S. trutta, and Leuciscus spp.), included zero for 6 species (B. barbus, R. amarus, S. cephalus, B. barbatula, A. bipunctatus, and Phoxinus spp.) and positive for Cottus spp. (Figure 4; Appendix S3). Population growth rate in biomass included zero for 3 species (A. bipunctatus, Phoxinus spp., and R. amarus), positive for Cottus spp. and negative for the other 14 species (Figure 4; Appendix S3).

\section{3 | Fish-length trends}

Of the 90 quantile regression coefficients (five quantiles for 18 investigated species), 80 were negative (Appendix S4 and S5). The first component of PCA-2 built on the five regression coefficients explained $57.02 \%$ of the total variance (Figure $5 \mathrm{a}$ ). This first axis highlighted a (a)

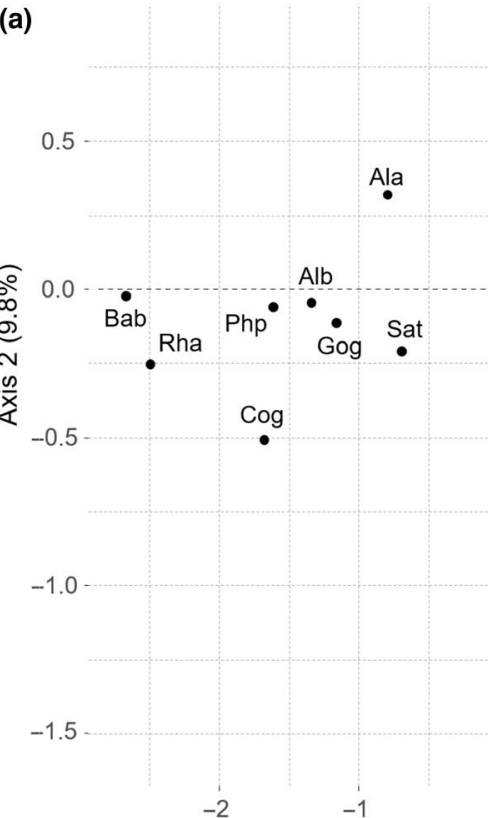

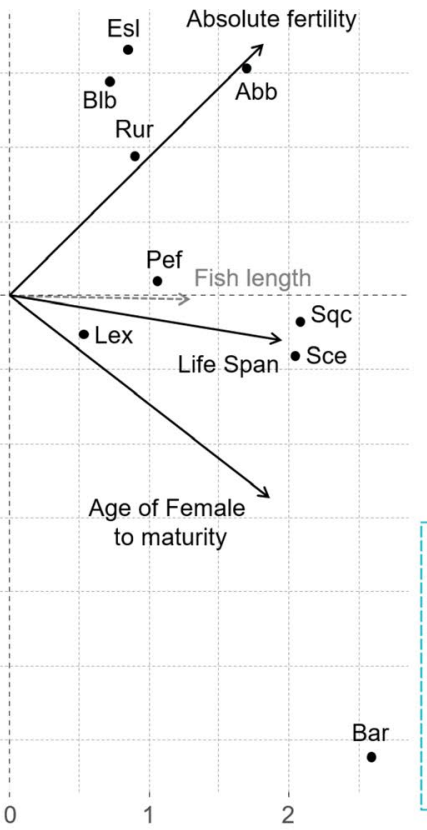

(b)

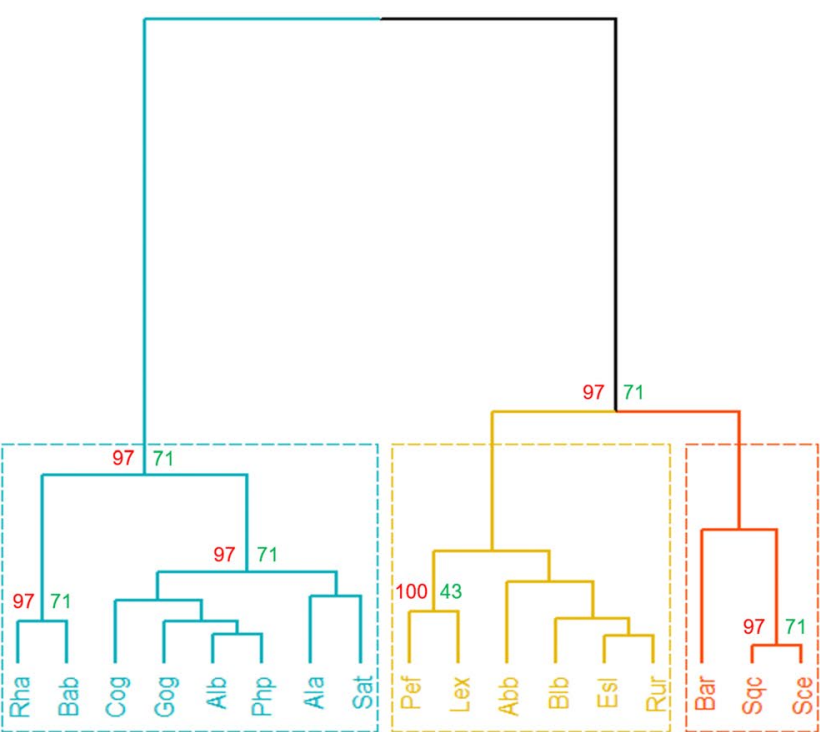

Axis $1(87.2 \%)$

FIGURE 3 Principal component analysis on fish life history traits (a) and dendogram of clusters (b). (a) Axis 1 accounts for $87.2 \%$ of between-species variability and axis 2 for $9.8 \%$. Grey arrows represent supplementary quantitative variables. (b) Values at branches are significant AU p-values (red), BP values (green). Abb: Abramis brama; Ala: Alburnus alburnus; Alb: Alburnoides bipunctatus; Ana: Anguilla Anguilla; Bab: Barbatula barbatula; Bar: Barbus barbus; Blb: Blicca bjoerkna; Cog: Cottus spp.; Esl: Esox Lucius; Gog: Gobio spp.; Lex: Leuciscus spp.; Pef: Perca fluviatilis; Php: Phoxinus spp.; Rha: Rhodeus amarus; Rur: Rutilus rutilus; Sat: Salmo trutta fario; Sce: Scardinius erythrophtalmus; Sqc: Squalius cephalus [Colour figure can be viewed at wileyonlinelibrary.com] 


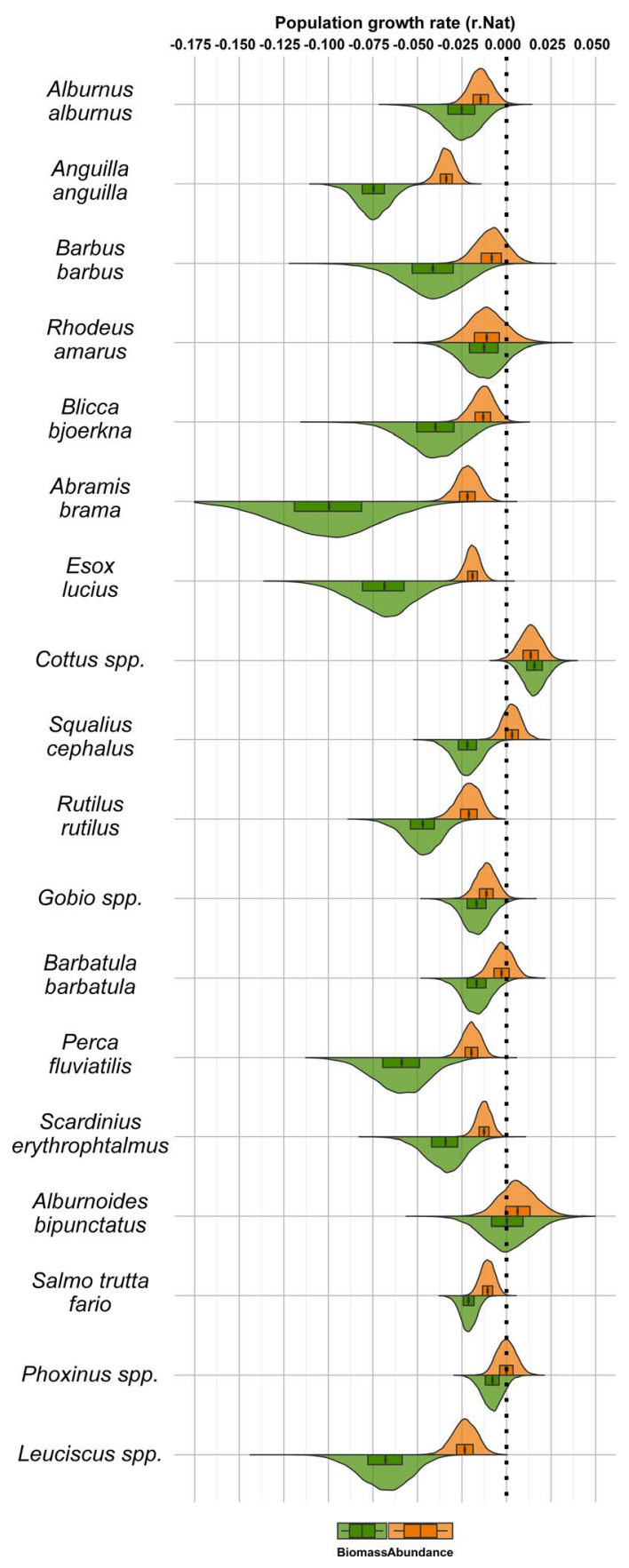

FIGURE 4 Posterior distribution of overall abundance (orange) and biomass (green) growth rates $\left(r_{\text {nat }}\right)$ of 18 common fish species in France from 1990 to 2011 by species. Boxes represent median values, and second and third quartiles of the posterior distribution values of the three chains ( $n=5,000$ by chain) [Colour figure can be viewed at wileyonlinelibrary.com]

slope gradient in fish length, contrasting species that showed a high decline in length to species that showed only slight or no decline in length. The second axis explaining $28.2 \%$ of the total variance mostly differentiated species with a relative decrease in larger individual's length ( 0.75 and 0.90 quantiles) from species showing a decrease in smaller individual's length (0.10 and 0.25 quantiles). The variation in quantile regression coefficients can be summarised by three clusters significantly discriminated ( $p<0.05 ; A U=96)$. The first cluster includes $A$. alburnus, R. amarus, Cottus spp., Gobio spp., Phoxinus spp., Anguilla anguilla, B. barbatula, and S. trutta and consists of fish species presenting a general decrease in fish length with a relatively smaller decrease in length of larger individuals (i.e. in terms of fish length) than in smaller individuals (Figure 5b). The second cluster includes R. rutilus, S. erythrophtalmus, B. bjoerkna, $P$. fluviatilis, A. bipunctatus, and $E$. lucius consists of fish species with a larger decrease in larger individual's length than in smaller individuals. The third cluster includes Leuciscus spp., S. cephalus, B. barbatula, and A. brama, in which a general decrease in fish length was observed, especially for larger fish. Species-specific scores on the first axis were then used as a synthetic variable called trends in fish length and species-specific scores on the second axis as trends in larger fish length.

\subsection{Correlations between growth rates, fish length, and demographic and ecological traits}

The first factorial plane of the PCA-3 performed with the abundance growth rate, biomass growth rate and fish length trend explained $76.28 \%$ of the total inertia (Figure 6a). The first component explained $51.11 \%$ of the total dataset variance, mostly due to the biomass and abundance growth rates, which were highly correlated with the first component ( 0.98 and 0.88 respectively). The variance in the second and third axis ( 25.17 and $21.96 \%$ of the total variance) was explained by the trends in fish length variable for 83.53 and $8.96 \%(0.91$ and -0.28 respectively) and by the trends in larger fish length variable for 21.54 and $61.36 \%$ (-0.39 and 0.78 respectively). The PCA-1 highlights that smaller fishes clustered together, united by increasing, relatively stable or slightly declining populations compare to large fishes which experienced drastic decline in abundance and biomass (Figure 6a). This interpretation is confirmed by hierarchical clustering analyses. Sixteen species were united into two significantly distinct clusters; one including B. barbatula, S. trutta, A. alburnus, R. amarus, A. anguilla, Cottus spp., Gobio spp., Phoxinus spp., gathering species with increasing or stable abundance and biomass over the last decades or experiencing moderate decline. Another gathering S. cephalus, Leuciscus spp., E. lucius, A. bipunctatus, B. bjoerkna, P. fluviatilis, $R$. rutilus, S. erythrophtalmus for which severe abundance and biomass decline have been highlighted for most of these species. A third cluster gathers both B. barbus and A. brama due to their trends in larger fish and biomass decline (Figure $6 \mathrm{~b}$ ). Of the supplementary quantitative variable investigated, the first axis is correlated with the species' fish length (-0.71) and demographic traits (-0.69; Figure 6a). Further investigation highlights a significant decrease in species population growth rates in biomass significantly correlated with increasing specific maximum standard length and fish demographic traits $(r=-0.67$, $p<0.01$ and $r=-0.61, p<0.01$ respectively; Figure 7a,b). A significant decrease in specific population growth rates in abundance was observed according to increasing specific maximum standard length ( $r=-0.49, p=0.02$ ) but a weak trend was observed in relation to fish life history traits $(r=-0.35, p=0.08$; Figure 7a,b). Of the qualitative life traits investigated, a between-class analysis highlighted 

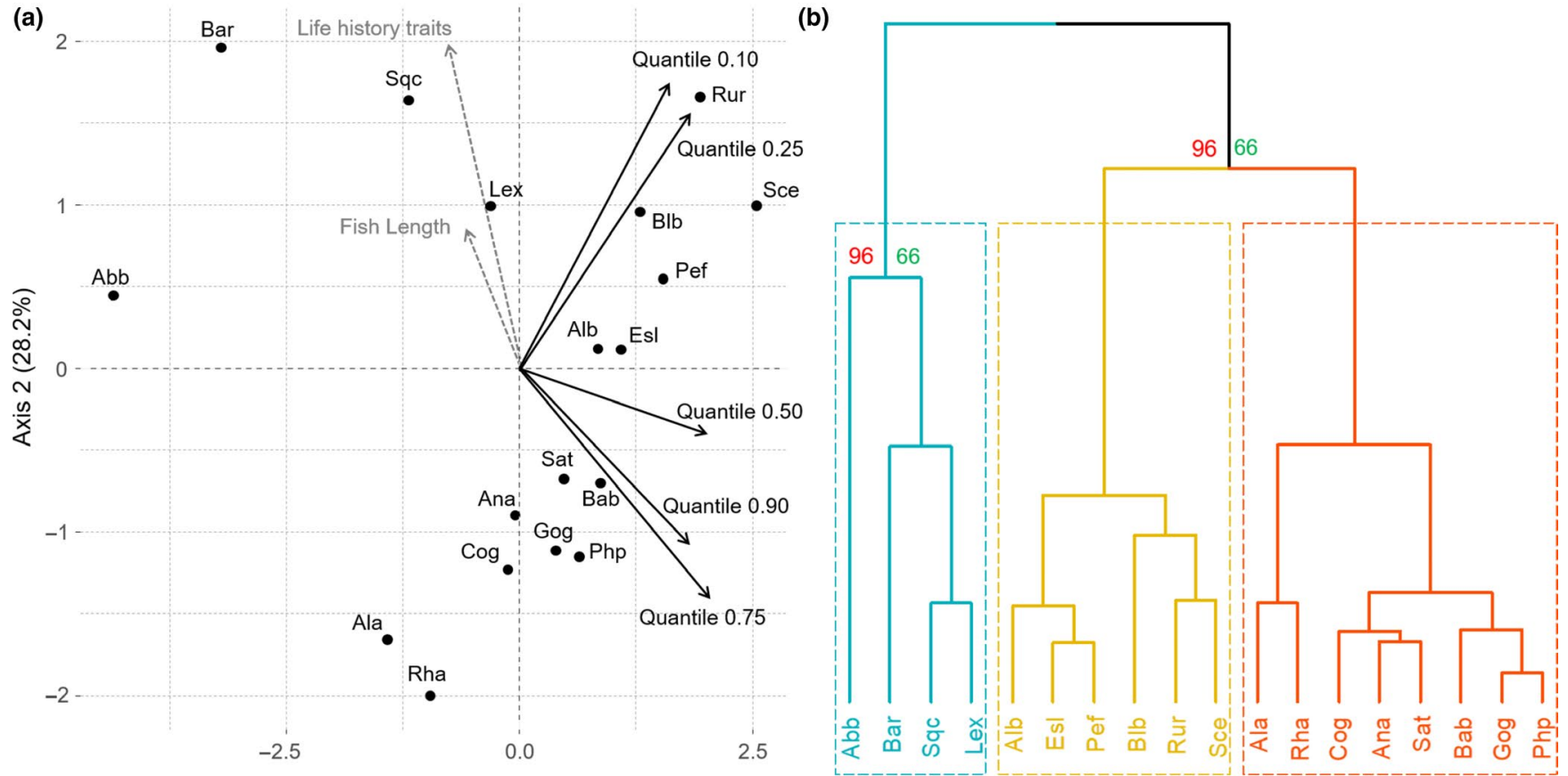

Axis $1(57.0 \%)$

FIGURE 5 Principal component analysis (a) of fish-length quantile regressions and cluster dendogram (b). A: axis 1 accounts for $57 \%$ of between-species variability and axis 2 for $28.2 \%$. Grey arrows represent supplementary quantitative variables. (b) Values at branches are significant AU p-values (red), BP values (green). Abb: Abramis brama; Ala: Alburnus alburnus; Alb: Alburnoides bipunctatus; Ana: Anguilla Anguilla; Bab: Barbatula barbatula; Bar: Barbus barbus; Blb: Blicca bjoerkna; Cog: Cottus spp.; Esl: Esox Lucius; Gog: Gobio spp.; Lex: Leuciscus spp.; Pef: Perca fluviatilis; Php: Phoxinus spp.; Rha: Rhodeus amarus; Rur: Rutilus rutilus; Sat: Salmo trutta fario; Sce: Scardinius erythrophtalmus; Sqc: Squalius cephalus [Colour figure can be viewed at wileyonlinelibrary.com]

that species' diet discriminates significantly species groups $(p<0.01$; Figure 8), omnivorous and invertivorous/piscivorous species exhibiting drastic population decline from invertivorous and herbivorous species exhibiting slight decline, stable or increasing abundance and biomass. Other qualitative traits were not significant (Appendix S6).

\section{4 | DISCUSSION}

Our results highlight that common and widely distributed freshwater fish species in France mostly exhibited nation-wide declines in abundance and biomass between 1990 and 2011. Our work demonstrates as well that large-bodied slow life-history species have exhibited higher population decline over the last decades than smaller-bodied fast life-history species. This observation accords with the general pattern observed worldwide in mammals, birds, reptiles and marine fish (Böhm et al., 2013; Cardillo et al., 2008; Gaston \& Blackburn, 1995; Lebreton, 2011; Reynolds, et al., 2005; Schipper et al., 2008).

\section{1 | Population dynamics of the most common freshwater fish since 1990}

A previous analysis of freshwater fish populations in France demonstrated that of the 48 taxa investigated, the number of species that had extended their distribution range and increased in density was greater than the number of declining species (Poulet et al., 2011). As French ichthyofauna is mainly composed of cool- and warm-water species as opposed to cold-water species, climate change was suggested as the main factor leading to the spatial expansion of these species as well as a decrease in nutrient concentrations that improved water quality over the last decades. In combination with the expansion of invasive species, this led to an increase in local species richness (Buisson \& Grenouillet, 2009; Poulet et al., 2011).

While the previous analysis was carried out on 48 freshwater fish taxa, we restricted our study to the 18 most common taxa. Our findings show for the period 1990-2011 that 11 species exhibited significant decline in abundance, and 14 species exhibited decline in biomass. Of the 18 species, six remained stable and one exhibited positive abundance growth rate; three species remained stable in biomass and one species significantly increased. The intra-specific fish -length trends over the studied period also showed a sharp decrease in size in the largest individuals ( 0.75 and 0.90 quantiles) correlated with high biomass declines in several species (for instance, $A$. brama, B. bjoerkna, B. barbus, E. lucius, and Leuciscus spp.).

In most fish species, fecundity generally increases allometrically with body length, as the largest females devote a greater proportion of energy to egg production than to growth (Lester et al., 2004). Thus, the observed decrease in the size of the largest individuals, concomitant with the drastic decline in biomass, may reflect progressive alterations in the population size/age structure, 


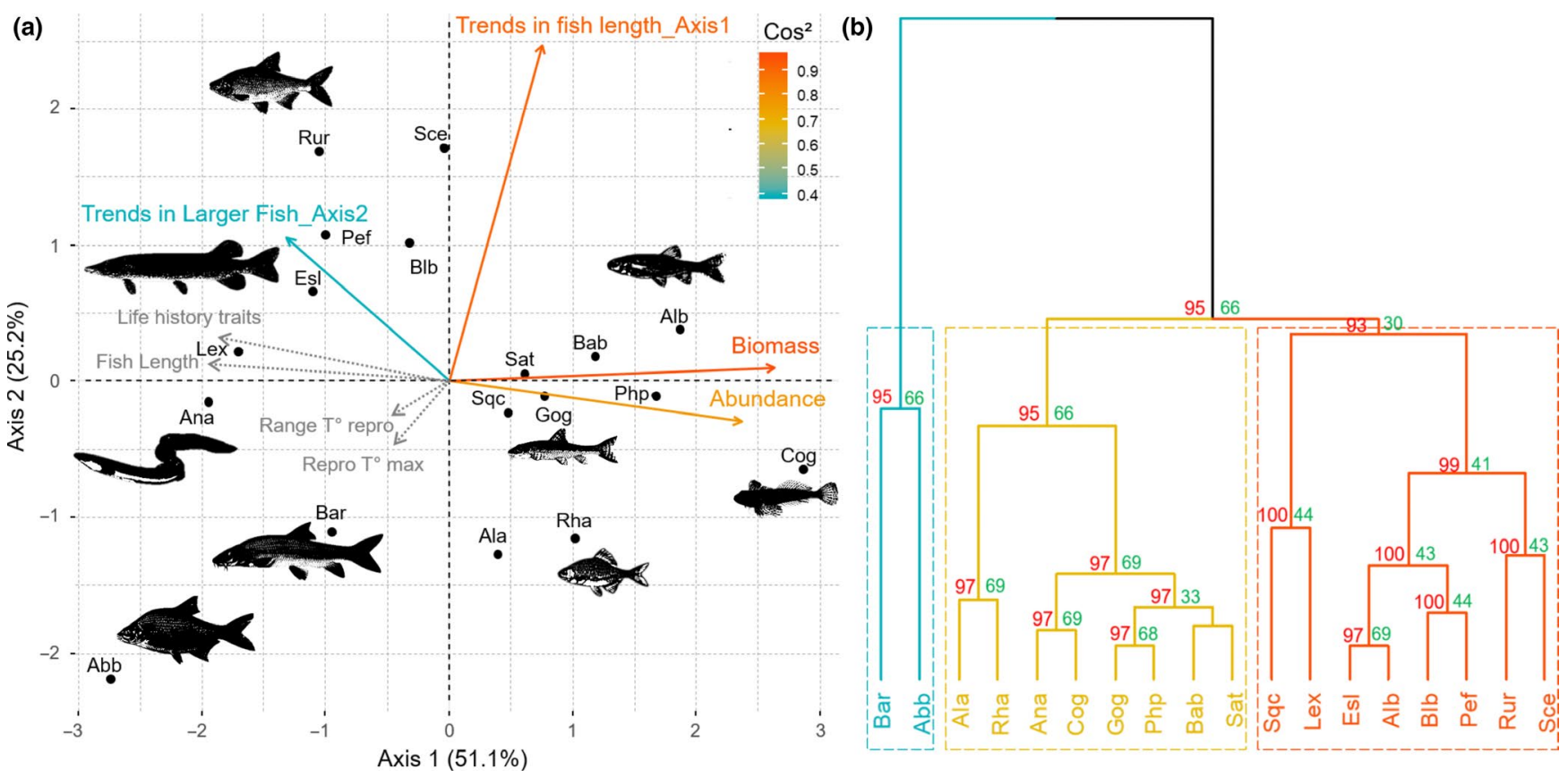

FIGURE 6 Principal component analysis of abundance, biomass and fish-length trends and cluster dendogram (b). (a) axis 1 accounts for $51.1 \%$ of between-species variability and axis 2 for $25.2 \%$. Grey arrows represent supplementary quantitative life history traits of species. (b) Values at branches are significant AU p-values (red), BP values (green). Abb: Abramis brama; Ala: Alburnus alburnus; Alb: Alburnoides bipunctatus; Ana: Anguilla Anguilla; Bab: Barbatula barbatula; Bar: Barbus barbus; Blb: Blicca bjoerkna; Cog: Cottus spp.; Esl: Esox Lucius; Gog: Gobio spp.; Lex: Leuciscus spp.; Pef: Perca fluviatilis; Php: Phoxinus spp.; Rha: Rhodeus amarus; Rur: Rutilus rutilus; Sat: Salmo trutta fario; Sce: Scardinius erythrophtalmus; Sqc: Squalius cephalus [Colour figure can be viewed at wileyonlinelibrary.com]

which should be further analysed. Such alterations in the population structure and size of common species might induce further cascading effects on the entire food web or might have been a consequence of altered food chains. Compared to declines in rare species, even small reductions in the widespread common species we studied may have resulted in substantial large-scale changes in ecosystem structure and function as these species represent $94.1 \%$ of fish abundance and $88.4 \%$ of fish biomass (Gaston, 2010; Gaston \& Fuller, 2008; Inger et al., 2015). To illustrate, the Huet zonation concept has been used for decades to distinguish and characterise western Europe rivers in four zones along the longitudinal gradient according to their habitats and fish assemblages: the trout zone, the grayling zone, the barbel zone and the bream zone (Huet, 1959). All these dominant species which shape riverine fish assemblages in western Europe are declining in abundance and/or biomass according to our results and previous investigations (Persat, 1996). The resulting depiction of fish population dynamics in France considering only common species in our study, is thus clearly not as positive as that outlined by Poulet et al. (2011). We show that from 1990 to 2011, the population abundance of common European fish have declined drastically along with reduced fish biomass; thus we recommend improving conservation measures for these widespread species.

Of the declining species we studied, the emblematic A. anguilla and $E$. lucius are respectively ranked as Critically Endangered and Vulnerable by the IUCN in France (UICN France, 2019). The population decline of A. anguilla and S. trutta are well documented in
European countries due to their high social and economic value, and they are the subject of Europe-wide or local conservation programmes (European Commission 1100/2007). Taxonomic units that include several newly identified species such as Leuciscus spp., Gobio spp., Cottus spp., and Phoxinus spp. involve sister species that experienced allopatric or peripatric speciation in France (Kottelat \& Freyhof, 2007). Despite possible introgression zones between sister species, it would be necessary to assess population trends at a lower geographic scale focus on these newly identified species. Some of them are classified as Nearly Threatened or even Critically Endangered and may exhibit different trends in populations than taxonomic unit population trends investigated at the nation-wide scale (UICN France, 2019). However, other taxa such as A. brama, $R$. rutilus, $P$. fluviatilis, and S. erythrophtalmus, for which we found severe declines, are considered as Least Concern or data deficient by the IUCN as the global persistence of those species is not imperilled in the short term (UICN France, 2019). To pay more attention to the status and population dynamics of common species, Gaston and Fuller (2008) envisaged a categorisation of species based on their level of population depletion to supplement IUCN extinction risk status. Furthermore, they have highlighted when population trends were more accurately assessed, the status of many common mammal, bird, and fish species have frequently been moved from Least Concern to Vulnerable or even Threatened with Extinction, underlining the importance of paying more attention to the conservation of common species through population trends analyses. 

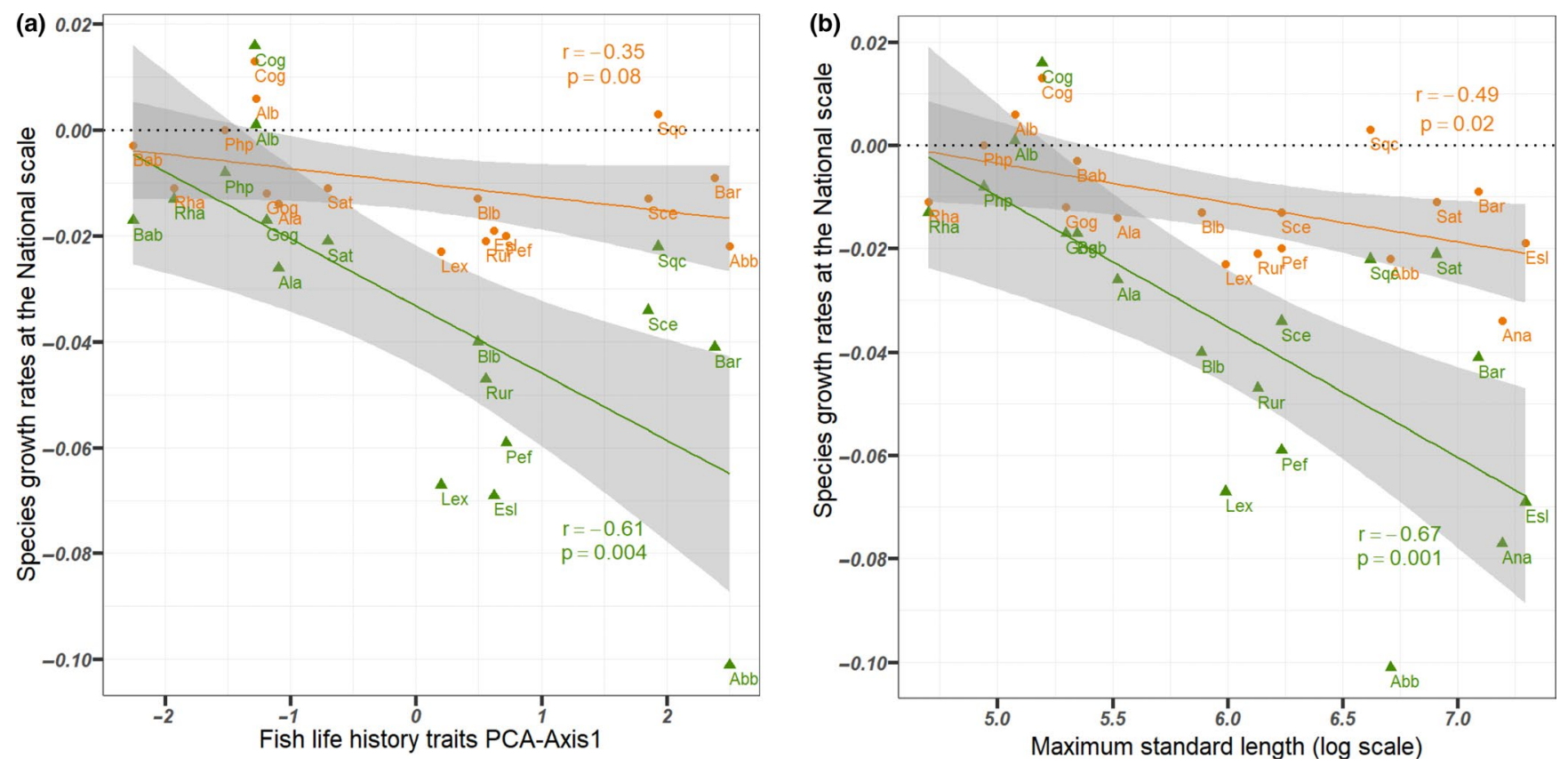

FIGURE 7 Relationship between median posterior values of specific population growth rates $\left(r_{\text {nat }}\right)$ in abundance (orange) or in biomass (green) and a) fish demographic traits (higher values for principal component analysis (PCA)-1 axis 1correspond to a slower life history strategy) and b) species standard length (log scale in $\mathrm{mm}$ ). Solid lines represent linear regressions and grey bands are $95 \%$ confidence intervals. Abb: Abramis brama; Ala: Alburnus alburnus; Alb: Alurnoides bipunctatus; Ana: Anguilla Anguilla; Bab: Barbatula barbatula; Bar: Barbus barbus; Blb: Blicca bjoerkna; Cog: Cottus spp.; Esl: Esox Lucius; Gog: Gobio spp. Gobio spp.; Lex: Leuciscus spp.; Pef: Perca fluviatilis; Php: Phoxinus spp.; Rha: Rhodeus amarus; Rur: Rutilus rutilus; Sat: Salmo trutta fario; Sce: Scardinius erythrophtalmus; Sqc: Squalius cephalus [Colour figure can be viewed at wileyonlinelibrary.com]

\section{2 | Relationship between population dynamics, ecological, and life-history traits}

Three life history strategies, periodic, opportunistic, and equilibrium, have been recognised for fish species (Winemiller \& Rose, 1992). The three investigated demographic traits (life span, age of female at maturity and the absolute fecundity) discriminated significantly small-sized opportunistic species from larger periodic species. Even though we did not consider parental care life traits due to the low variability of these variables among the investigated species (Buisson \& Grenouillet, 2009), our synthetic variable discriminated species life history traits on a slow-fast life history strategy continuum. Clusters from the hierarchical clustering analyses grouped fish with fast life histories considered hereafter as short-lived opportunistic strategists and species with slow life histories considered hereafter as long-lived periodic strategists. Of the demographic and ecological traits we investigated, species maximum body length, demographic traits, and fish diet were significant and most strongly correlated with population growth rates. Linear regressions highlighted significant relationships between species growth rates in biomass, body length, and demographic traits, and between trends in abundance and fish body length. Biomass data could be less influenced by young-ofthe-year than abundance data, which could explain stronger relations with traits, increase power of long-term trend detection and could explain the higher magnitude of decline in biomass (Pregler et al., 2019). The general pattern observed through this holistic approach highlighted that despite most of the 18 common species exhibiting significant declines in biomass and abundance, larger periodic species have declined most strongly, while smaller opportunistic species exhibited a moderate decline, were stable or even increased in abundance and biomass. Amongst the seven species that were stable or increased in abundance since 1990, five of them are opportunistic species but the two others, B. barbus and $S$. cephalus, are large-sized periodic species. Both species considered as ubiquitous species spawn multiple times during a reproductive season that may favour young-of-the-year and juvenile survival, which would explain that these species exhibit stable population growth rates in abundance but significantly declined in biomass.

A previous study concluded that threatened species of European freshwater fishes are smaller-bodied species (Reynolds, et al., 2005b). They mentioned the body size relationship was not detected when large-bodied anadromous species were analysed suggesting that risks of extinction depend as well on species migratory behaviours. Our results are complementary to Reynolds, et al. (2005) as widely distributed European common species here studied are far from extinction and are not anadromous species, but most are declining nonetheless exhibiting body size and life history traits relationships with nation-wide population growth rates. In contrast to fast life history fish species, which are favoured in environments characterised by frequent and intense disturbances, slow life history species are favoured when environmental variation is low or moderate and relatively predictable (Mims \& Olden, 2012; 


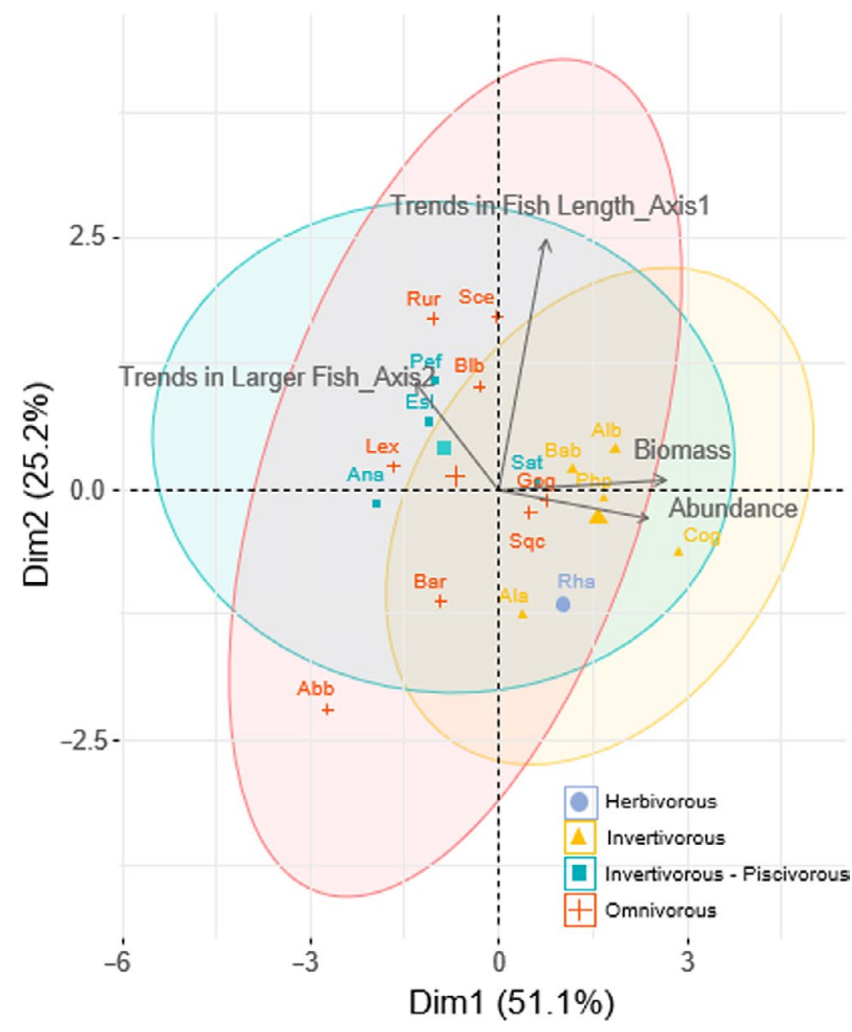

FIGURE 8 Principle component analysis performed on abundance, biomass and fish-length trends and $0.95 \%$ confidence interval ellipses associated to life traits considering species' diet. Confidence interval ellipses are estimated if at least 4 species are within the same category. Abb: Abramis brama; Ala: Alburnus alburnus; Alb: Alurnoides bipunctatus; Ana: Anguilla Anguilla; Bab: Barbatula barbatula; Bar: Barbus barbus; Blb: Blicca bjoerkna; Cog: Cottus spp.; Esl: Esox Lucius; Gog: Gobio spp.; Lex: Leuciscus spp.; Pef: Perca fluviatilis; Php: Phoxinus spp.; Rha: Rhodeus amarus; Rur: Rutilus rutilus; Sat: Salmo trutta fario; Sce: Scardinius erythrophtalmus; Sqc: Squalius cephalus [Colour figure can be viewed at wileyonlinelibrary.com]

Winemiller \& Rose, 1992). In frequently disturbed areas, periodic species are predisposed to population decline due to their low intrinsic maximum population growth rate, limiting their ability to recover after perturbations (Stearns, 1992; Saether \& Engen, 2002; Lebreton, 2011). According to our results on common fish, periodic species have probably been jeopardised by global pressures impacting their population dynamics on a large scale for decades.

\section{3 | Fish species threatened by global pressures}

To provide science-based guidance to environmental managers and policy makers, anthropogenic and environmental factors that most strongly impact population growth rates in abundance and biomass of common species must be identified to reverse species decline. As described by Ohlberger (2013) in ectotherms, the water temperature warming experienced in France from climate change may have led to a 'size at age shift' (a decrease in body size), a 'structure shift' (competitive asymmetry in favour of smaller individuals) and a community 'composition shift' (smaller species replacing larger competitors) as observed in our study as well as previous studies (Daufresne et al., 2009; Edeline et al., 2013). Nevertheless, the rapid and drastic intra-specific decrease in the length of the largest and probably oldest fish observed in a short period (12 years) in long-lived species-while the median lengths of these species have remained stable over time (such as B. bjoerkna, A. brama, Leuciscus spp., R. rutilus, and E. lucius; see Appendix S5, S6) - might reflect effects of other pressures than only impacts of climate changes. Our results in fish-length trends, concomitant to a reduction in the biomass and abundance of longlived species, suggest that a decrease in growth and survival might be responsible for the observed patterns. This is in line with Grenouillet and Comte (2014) and Kuczynski et al. (2018), who demonstrated that cumulative anthropogenic pressures have influenced the distribution and communities of fish species in France over recent decades.

Multiple pressures altering body growth and survival could explain the sharp decrease in upper-quantile fish size. Among them, hydro-morphological change and water pollution are considered as the most impacting ones affecting 40 and $38 \%$ of European surface water, respectively (European Environment Agency, 2018). Fish exposure to a mixture of micropollutants with various modes of toxic action can lead to direct or delayed biological impacts through transgenerational effects, population structure disturbances, and decrease in population growth rates (Devaux et al., 2015; Heintz, 2007; Heintz et al., 2000; Rowe, 2008). Thus, degradation of water quality by micropollutants at a large scale (European Environment Agency, 2018; Malaj et al., 2014) could be responsible for decreasing juvenile and adult survival in longlived fish species, possibly exacerbated by the fact that slow turnover means these species have slow genetic adaptation to chemical pressures (Rowe, 2008). Hydro-morphological pressures have also degraded and reduced essential key habitats (Aarts et al., 2004; European Environment Agency, 2018). In the U.S.A., the prevalence of periodic strategists is favoured by seasonally predictable events (high duration flows) that enable access to spawning and floodplain habitats and resources (Mims \& Olden, 2012). Moreover hydro-morphological alterations may have impacted the anadromous species Anguilla anguilla and declining potamodromous species. Scharbert and Borcherding (2013) showed that young of the year of western Europe periodic species were highly abundant in waterbodies frequently inundated during the breeding season pointing out that mitigating hydro-morphological pressures is effective to favour slow life-histories species recovery.

Elasticity and sensitivity of population growth rate analyses implemented on a wide array of vertebrate species defined the relative contribution of demographic parameters to population growth rates. It is well acknowledged that population growth rate of slow life-history strategists is most sensitive to alterations in adult and juvenile survival compare to a decrease in fecundity or embryo-larval survival (Saether \& Bakke, 2000; Vélez-Espino et al., 2006; Mangel et al., 2006; Gamelon et al., 2015). Therefore, any pressures impacting adult and juvenile survival must be identified and mitigated as a priority to favour the recovery of slow life-history species. 


\subsection{Focusing on conservation strategies for slow life-history species}

A key challenge in planning the most appropriate conservation strategies based on scientific evidence is the lack of knowledge regarding fish ecology and vital rates, even for common species. It is crucial to acknowledge which lifecycle components contribute most to a species' population growth rate to tackle population decline (Velez-Espino et al., 2006). Of the declining species identified in our study, A. alburnus and Leuciscus spp. have been shown to consistently respond positively to habitat restoration (Thomas et al., 2015). To a lesser extent, the other declining species $S$. trutta, B. barbus, A. brama, E. lucius, R. rutilus, and S. erythrophtalmus also responded positively to hydro-morphological restoration (Thomas et al., 2015). Manfrin et al. (2019) demonstrated a clear succession of functional patterns where, in the short-term, opportunistic species benefited from restoration measures in Europe while periodic fish species became more prevalent in the long-term. Due to their low intrinsic maximum population growth rate and low density, periodic species need time to recover after restoration projects.

\section{5 | Conclusions}

These results support that analysing extinction risks and population dynamics are different but complementary approaches, and that fish conservation planning should not rely solely on one approach. Declining and vulnerable species are amongst rare and common species. Focusing our efforts on only one will not enhance freshwater fish conservation as a whole.

It would be of great interest to assess at a larger scale if population dynamic patterns observed in France in common European species are similar in countries where environmental and anthropogenic pressures are similar. Conversely, it is likely that species population growth varies among drainage basins. Thus, it would be beneficial to investigate species population growth rates in abundance and biomass at a lower geographic scale to define region-specific management and conservation priority. This work clearly highlights the crucial value of monitoring programmes via standardised electrofishing protocols to assess freshwater fish species population trajectories and implement environmental management and policy based on scientific evidence. We demonstrated the importance of life history variation on the fast-slow continuum that is correlated with freshwater fish population growth rates in abundance and biomass. Thus, it will be crucial to identify the multiple global pressures explaining large-scale decline of most of the species, and especially large-sized slow-life history species in order to mitigate them. Using sensitivity and elasticity analyses, it will be essential to identify demographic parameters with the greatest potential to affect population growth rate in order to favour the recovery of declining species. To favour slow-life history species in particular, conservation management strategies should focus on measures that increase juvenile and adult survival as a priority, as population growth in these species is mainly driven by these demographic components (as opposed to a decrease in fecundity or embryo-larval survival). Several river restoration projects have aided the recovery of these declining species, but a valuable next step would be to identify restoration measures with the most success in increasing the population growth rate of the declining species, especially slow life-history species.

\section{ACKNOWLEDGEMENTS}

The authors are grateful to the French Office for Biodiversity for funding. We would also like to thank everyone involved in conducting the field survey since 1990 (the staff of the National Agency for Water and Aquatic Environments, formerly the French Fisheries Council), to whom this work is dedicated. We also thank the BGSL group and Jane O'Rourke for the valuable comments and advices, which improved the manuscript. The authors are deeply thankful to Dr Mary Freeman (associate editor of Freshwater Biology) and the anonymous reviewers for their insightful and constructive comments which drastically improved the manuscript.

\section{CONFLICT OF INTERESTS}

The authors declare that they have no conflict of interests.

\section{AUTHOR CONTRIBUTIONS}

R.S., A.B., and N.P. designed the study; R.S. and A.B. analysed the data and wrote the manuscript; N.P. provided the data and funding to carry out the study and commented on the manuscript.

\section{DATA AVAILABILITY STATEMENT}

The authors declare that the data and model codes supporting the findings of this study are available within the paper or its Supplementary Information files, or from the corresponding author on reasonable request.

\section{ORCID}

Raphaël Santos (iD https://orcid.org/0000-0002-4800-5180

\section{REFERENCES}

Aarts, B. G. W., Van Den Brink, F. W. B., \& Nienhuis, P. H. (2004). Habitat loss as the main cause of the slow recovery of fish faunas of regulated large rivers in Europe: The transversal floodplain gradient. River Research and Applications, 20(1), 3-23.

Balian, E. V., Segers, H., Lévèque, C., \& Martens, K. (2008). The freshwater animal diversity assessment: An overview of the results. Hydrobiologia, 595, 627-637.

Böhm, M., Collen, B., Baillie, J. E. M. et al (2013). The conservation status of the world's reptiles. Biological Conservation, 157, 372-385.

Brooks, S. P., \& Gelman, A. (1998). Alternative methods for monitoring convergence of iterative simulations. Journal of Computational and Graphical Statistics, 7, 434-455.

Buisson, L., \& Grenouillet, G. (2009). Contrasted impacts of climate change on stream fish assemblages along an environmental gradient. Diversity and Distributions, 15(4), 613-626.

Cade, B. S., \& Noon, B. R. (2003). A gentle introduction to quantile regression for ecologists. Frontiers of Ecology and Environment, 1(8), 412-420. 
Cardillo, M., Mace, G. M., Gittleman, J. L., Jones, K. E., Bielby, J., \& Purvis, A. (2008). The predictability of extinction : Biological and external correlates of decline in mammals. Proceedings of the Royal Society of London Series B - Biological Sciences, 275, 1441-1448.

Chamaillé-Jammes, S., \& Blumstein, D. T. (2012). A case for quantile regression in behavioral ecology: Getting more out of flight initiation distance data. Behavioral Ecology and Sociobiology, 66, 985-992.

UICN Comité Français, MNHN, SFI, AFB (2019). La Liste rouge des espèces menacées en France - Chapitre Poissons d'eau douce de France métropolitaine (15 pp). : UICN Comité Français, MNHN, SFI, AFB.

Costédoat, C., Chappaz, R., Barascud, B., Guillard, O., \& Gilles, A. (2006). Heterogeneous colonization pattern of European Cyprinids, as highlighted by the dace complex (Teleostei: Cyprinidae). Molecular Phylogenetics and Evolution, 41, 127-148.

Daufresne, M., Lengfellner, K., \& Sommer, U. (2009). Global warming benefits the small in aquatic ecosystems. Proceedings of the National Academy of Sciences of the United States of America, 31, 12788-12793.

De Valpine, P., \& Hastings, A. (2002). Fitting population models incorporating process noise and observation error. Ecological Monographs, 72(1), 57-76.

Décamps, H. (2011). River networks as biodiversity hotlines. Comptes Rendus Biologies, 334(5-6), 420-434.

Denwood, M. J. (2016). runjags: An R package providing interface utilities, model templates, parallel computing methods and additional distributions for MCMC models in JAGS. Journal of Statistical Software, 71(9), 1-25.

Devaux, A., Bony, S., Plenet, S., Sagnes, P., Segura, S., Suaire, R., ... Olivier, J. M. (2015). Field evidence of reproduction impairment through sperm DNA damage in the fish nase (Chondrostoma nasus) in anthropized hydrosystems. Aquatic Toxicology, 169, 113-122.

Dray, S., Dufour, A. B., \& Chessel, D. (2007). The ade4 package-II: Twotable and K-table methods. $R$ News, 7(2), 47-52.

Edeline, E., Lacroix, G., Delire, C., Poulet, N., \& Legendre, S. (2013). Ecological emergence of thermal clines in body size. Global Change Biology, 19(10), 3062-3068.

European Environment Agency (2012). European waters-assessment of status and pressures. EEA Report No. 8 (p. 96). EEA.

European Environment Agency (2018). European waters-assessment of status and pressures 2018. EEA Report No. 7/2018 (p. 85). EEA.

Freyhof, J., \& Brooks, E. (2011). European red list of freshwater fishes (p. 61). Publication Office of the European Union.

Fromentin, J. M., Myers, R. A., Bjørnstad, O. N., Stenseth, N. C., Gjøsæter, J., \& Christie, H. (2001). Effects of density-dependent and stochastic processes on the regulation of cod populations. Ecology, 82(2), 567-579.

Furrer, R., Schaub, M., Bossert, A., Isler, R., Jenny, H., Jonas, T., ... Jenni, L. (2016). Variable decline of Alpine Rock Ptarmigan (Lagopus muta helvetica) in Switzerland between regions and sites. Journal of Ornithology, 157(3), 787-796.

Gaillard, J.-M., Yoccoz, N. G., Lebreton, J.-D., Bonenfant, C., Devillard, S., Loison, A., ... Allaine, D. (2005). Generation time: A reliable metric to measure life-history variation among mammalian populations. The American Naturalist, 166(1), 119-123.

Gamelon, M., Gaillard, J.-M., Gimenez, O., Coulson, T., Tuljapurkar, S., \& Baubet, E. (2015). Linking demographic responses and life history tactics from longitudinal data in mammals. Oikos, 125, 395-404.

Gaston, K. J. (2010). Ecology. Valuing common species. Science, 327(5962), 154-155.

Gaston, K. J., \& Blackburn, T. M. (1995). Birds, body size and the threat of extinction. Philosophical Transactions of the Royal Society B: Biological Sciences, 347, 205-212.

Gaston, K. J., \& Fuller, R. A. (2008). Commonness, population depletion and conservation biology. Trends in Ecology and Evolution, 23(1), 14-19.
Grenouillet, G., \& Comte, L. (2014). Illuminating geographical patterns in species' range shifts. Global Change Biology, 20, 3080-3091.

Heintz, R. A. (2007). Chronic exposure to polynuclear aromatic hydrocarbons in natal habitats leads to decreased equilibrium size, growth, and stability of pink salmon populations. Integrated Environmental Assessment and Management, 3(3), 351-363.

Heintz, R. A., Rice, S. D., Wertheimer, A. C., Bradshaw, R. F., Thrower, F. P., Joyce, J. E., \& Short, J. W. (2000). Delayed effects on growth and marine survival of pink salmon Oncorhynchus gorbuscha after exposure to crude oil during embryonic development. Marine Ecology Progress Series, 208, 205-216.

Helfman, G. S. (2007). Fish conservation: A guide to understanding and restoring global aquatic biodiversity and fishery resources (p. 584). Island Press.

Holzer, S. (2008). European fish species: taxa and guilds classification regarding fish-based assessment methods, Ph.D. thesis, Universitat fur Bodenkultur, pp. 192.

Huet, M. (1959). Profiles and biology of western European streams as related to fisheries management. Transactions of the American Fisheries Society, 88, 155-163.

Husson, F., Josse, J., Le, S., \& Mazet, J. (2015). FactoMineR: Multivariate Exploratory Data Analysis and Data Mining. R package version 1.29. http://CRAN.R-project.org/package=FactoMineR

Inger, R., Gregory, R., Duffy, J. P., \& Stott, I. (2015). Common European birds are declining rapidly while less abundant species' numbers are rising. Ecology Letters, 18, 28-36.

IUCN (2018). The IUCN Red List of Threatened Species. Version 2018-1. Retrieved from http://www.iucnredlist.org

Jelks, H. L., Walsh, S. J., Burkhead, N. M., Contreras-Balderas, S., DíazPardo, E., Hendrickson, D. A., Warren, M. L. (2008). Conservation status of imperiled North American freshwater and diadromous fishes. Fisheries, 33, 327-407.

Julliard, R., Jiguet, F., \& Couvet, D. (2003). Common birds facing global changes: What makes a species at risk? Global Change Biology, 10, 148-154.

Karr, J. R. (1981). Assessment of biotic integrity using fish communities. Fisheries, 6(6), 21-27.

Kéry, M., \& Schaub, M. (2012). Bayesian population analysis using WinBUGS (p. 302). Academic.

Knape, J., \& de Valpine, P. (2012). Are patterns of density dependence in the Global Population Dynamics Database driven by uncertainty about population abundance? Ecology Letters, 15(1), 17-23.

Koenker, R. (2005). Quantile regression. Econometric society monograph series. : Cambridge University Press.

Koenker, R. (2015). quantreg: Quantile Regression. R package version 5.11. Retrieved from http://CRAN.R-project.org/package=quantreg.

Kopf, R. K., Shaw, C., \& Humphries, P. (2017). Trait-based prediction of extinction risk of small-bodied freshwater fishes. Conservation Biology, 31(3), 581-591.

Kottelat, M., \& Freyhof, J. (2007) Handbook of European freshwater fishes. In M. Kottelat \& J. Freyhof (Eds.), pp. 646.

Kuczynski, L., Legendre, P., \& Grenouillet, G. (2018). Concomitant impacts of climate change, fragmentation and non-native species have led to reorganization of fish communities since the 1980s. Global Ecology and Biogeography, 27, 213-222.

Lebreton, J. D. (2011). The impact of global change on terrestrial vertebrates. C.R. Biologies, 334, 360-369.

Lester, N. P., Shuter, B. J., \& Abrams, P. A. (2004). Interpreting the Von Bertalanffy model of somatic growth in fishes: the cost of reproduction. Proceedings of the Royal Society of London Series B - Biological Sciences, 271, 1625-1631.

Logez, M., Bady, P., Melcher, A., \& Pont, D. (2013). A continental-scale analysis of fish assemblage functional structure in European rivers. Ecography, 36(1), 80-91. 
Malaj, E., Von Der Ohe, P. C., Grote, M., Kühne, R., Mondy, C. P., UsseglioPolatera, P., ... Schafer, R. B. (2014). Organic chemicals jeopardize the health of freshwater ecosystems on the continental scale. Proceedings of the National Academy of Sciences of the United States of America, 111, 9549-9554.

Manfrin, A., Teurlincx, S., Lorenz, A. W., Haase, P., Marttila, M., Syrjänen, J. T., ... Stoll, S. (2019). Effect of river restoration on life-history strategies in fish communities. Science of the Total Environment, 663, 486-495.

Mangel, M., Levin, P., \& Patil, A. (2006). Using life history and persistence criteria to prioritize habitats for management and conservation. Ecological Applications, 16(2), 797-806.

Marzin, A., Archaimbault, V., Belliard, J., Chauvin, C., Delmas, F., \& Pont, D. (2012). Ecological assessment of running waters: Do macrophytes, macroinvertebrates, diatoms and fish show similar responses to human pressures? Ecological Indicators, 23, 56-65.

Millenium Ecosystem Assessment (2005). Ecosystems and human well-being, Vol. 5. Island Press.

Mims, M. C., \& Olden, J. D. (2012). Life history theory predicts fish assemblage response to hydrologic regimes. Ecology, 93(1), 35-45.

Møller, A. P., Rubolini, D., \& Lehikoinen, E. (2008). Populations of migratory bird species that did not show a phenological response to climate change are declining. Proceedings of the National Academy of Sciences of the United States of America, 105, 16195-16200.

Newman, K. B., Buckland, S. T., Morgan, B. J. T., King, R., Borchers, D. L., Cole, D. J., ... Thomas, L. (2014). Modelling population dynamics: Model formulation, fitting and assessment using state-space methods, methods in statistical ecology (p. 215). Springer Science.

Ohlberger, J. (2013). Climate warming and ectotherm body size: From individual physiology to community ecology. Functional Ecology, 27(4), 991-1001.

Olden, J. D., Hogan, Z. S., \& Zanden, M. J. V. (2007). Small fish, big fish, red fish, blue fish: Size-biased extinction risk of the world's freshwater and marine fishes. Global Ecology and Biogeography, 16(6), 694-701.

Persat, H. (1996). Threatened populations and conservation of the European grayling, Thymallus thymallus (L., 1758). In A. Kirchhofer \& D. Hefti (Eds.), Conservation of endangered freshwater fish in Europe (p. 233). Birkhäuser Basel: ALS Advances in Life Sciences.

Plummer, M. (2003). JAGS: A program for analysis of Bayesian graphical models using Gibbs sampling. Proceedings of the 3rd International Workshop on Distributed Statistical Computing (DSC 2003): 20-22.

Poulet, N., Beaulaton, L., \& Dembski, S. (2011). Time trends in fish populations in the metropolitan France: Insights from national monitoring data. Journal of Fish Biology, 79, 1436-1452.

Pregler, K. C., Hanks, D. R., Childress, E. S., Hitt, N. P., Hocking, D. J., Letcher, B. H., ... Kanno, Y. (2019). State-space analysis of power to detect regional brook trout population trends over time. Canadian Journal of Fisheries and Aquatic Sciences, 76(11), 2145-2155.

R Development Core Team (2015). R: A language and environment for statistical computing. R Foundation for Statistical Computing. https:// www.R-project.org/.

Reynolds, J. D., Dulvy, N. K., Goodwin, N. B., \& Hutchings, J. A. (2005). Biology of extinction risk in marine fishes. Proceedings of the Royal Society B: Biological Sciences, 272, 2337-2344.

Reynolds, J. D., Webb, T. J., \& Hawkins, L. A. (2005). Life history and ecological correlates of extinction risk in European freshwater fishes. Canadian Journal of Fisheries and Aquatic Science, 62, 854-862.

Rowe, C. L. (2008). "The calamity of so long life": Life histories, contaminants, and potential emerging threats to long-lived vertebrates. BioScience, 58(7), 623-631.

Saether, B. E. R., \& Bakke, Ø. (2000). Avian life history variation and contribution of demographic traits to the population growth rate. Ecology, 81, 642-653.
Saether, B. E. R., \& Engen, S. (2002). Pattern of variation in avian population growth rates. Philosophical Transactions of the Royal Society of London. Series B, Biological Sciences, 357(1425), 1185-1195.

Santos, R., Joyeux, A., Besnard, A., Blanchard, C., Halkett, C., Bony, S., Sanchez, W., \& Devaux, A. (2017). An integrative approach to assess ecological risks of river contamination for fish populations. Environmental Pollution, 220, 588-596.

Scharbert, A., \& Borcherding, J. (2013). Relationships of hydrology and life-history strategies on the spatio-temporal habitat utilization of fish in European temperate river floodplains. Ecological Indicators, 29, 348-360.

Schipper, J., Chanson, J. S., \& Chiozza, F. (2008). The status of the world's land and marine mammals: Diversity, threat, and knowledge. Science, 322, 225-230.

Schmutz, S., Cowx, I. G., Haidvogl, G., \& Pont, D. (2007). Fish-based methods for assessing European running waters: A synthesis. Fisheries Management and Ecology, 14, 369-380.

Schönhuth, S., Vukic, J., Sanda, R., Yang, L., \& Mayden, R. L. (2018). Phylogenetic relationships and classification of the Holarctic family Leuciscidae (Cypriniformes: Cyprinoidei). Molecular Phylogenetics and Evolution, 127, 781-799.

Stearns, S. C. (1992). The evolution of life histories. Oxford University Press.

Suzuki, R., \& Shimodaira, H. (2006). Pvclust: An R package for assessing the uncertainty in hierarchical clustering. Bioinformatics, 22(12), 1540-1542.

Thomas, G., Lorenz, A. W., Sundermann, A., Haase, P., Peter, A., \& Stoll, S. (2015). Fish community responses and the temporal dynamics of recovery following river habitat restorations in Europe. Freshwater Science, 34(3), 975-990.

Tissot, L., \& Souchon, Y. (2010). Synthèse des tolérances thermiques des principales espèces de poissons des rivières et fleuves de plaine de l'ouest européen. Hydroécologie Appliquée, 17, 17-76.

Vélez-Espino, L. A., Fox, M. G., \& McLaughlin, R. L. (2006). Characterization of elasticity patterns of North American freshwater fishes. Canadian Journal of Fisheries and Aquatic Science, 63(9), 2050-2066.

Vila-Gispert, A., \& Moreno-Amich, R. (2002). Life-history patterns of 25 species from European freshwater fish communities. Environmental Biology of Fishes, 65, 387-400.

Winemiller, K. O., \& Rose, K. A. (1992). Patterns of life-history diversification in North American fishes: Implications for population regulation. Canadian Journal of Fisheries and Aquatic Science, 49, 2196-2218. https://doi.org/10.1139/f92-242

Winemiller, K. O. (2005). Life history strategies, population regulation, and implications for fisheries management. Canadian Journal of Fisheries and Aquatic Science, 62(4), 872-885. https://doi.org/10. 1139/f05-040

\section{SUPPORTING INFORMATION}

Additional supporting information may be found online in the Supporting Information section.

How to cite this article: Santos R, Poulet N, Besnard A. Life-history traits correlate with temporal trends in freshwater fish populations for common European species. Freshwater Biology. 2021;66:317-331. https://doi.org/10.1111/fwb.13640 